\title{
A Cross-Sectional Study on the Knowledge of Hepatitis B Infection among Dental Professionals
}

\author{
Sowmya Kasetty, Anubhuti Mohania, Dhara Dwivedi, Manisha Tijare, \\ Shreenivas Kallianpur and Sandeep Gupta
}

Dept of Oral Pathology, People's College of Dental sciences and Research Centre, Madhya Pradesh, India

Correspondence should be addressed to: Sowmya Kasetty; sowmyakasetty@gmail.com

Received 5 February 2013; Accepted 26 February 2013; Published 23 April 2013

Academic Editor: Oyinkansola Olulola Sofola

Copyright (C) 2013 Sowmya Kasetty, Anubhuti Mohania, Dhara Dwivedi, Manisha Tijare, Shreenivas Kallianpur and Sandeep Gupta. Distributed under Creative Commons CC-BY 3.0

\begin{abstract}
Background: Hepatitis B is an inflammatory disease of liver due to double stranded DNA virus of the hepadnaviridae, transmitted through contact with the blood or other body fluids of an infected person. Hepatitis B poses a major health concern and is the world's most common blood borne viral infection placing healthcare workers, medical and dental professionals at higher occupational risk and in India it is the second most common cause for acute hepatitis. To increase the awareness and knowledge about viral hepatitis WHO has declared $28^{\text {th }}$ July as the World Hepatitis Day/Eradication day. So the present survey was conducted to evaluate and compare the status of awareness of hepatitis B infection among dental practitioners and students.
\end{abstract}

Methodology: A questionnaire based study was conducted on a randomized sample of 280 dental professionals including dental practitioners, dental postgraduate students and dental interns. The collected data were analyzed using SPSS software.

Results \& Conclusion: The results obtained reveal that $58.21 \%$ dental professionals were ignorant about the investigation procedures \& diagnosis of hepatitis. While 82.15\%, 95.36\%, 58.22\% and 93. $93 \%$ had good knowledge about hepatitis infection and its transmission, vaccine, attitude towards HBV patients and post exposure prophylaxis respectively. However, the status of awareness among dental practitioners, postgraduate students and interns was found to be insignificant $(\mathrm{p}>0.05)$.

Keywords: Hepatitis B infection, Survey, Awareness, Dental students, Vaccinization, Post exposure prophylaxis

Cite this Article as: Sowmya Kasetty, Anubhuti Mohania, Dhara Dwivedi, Manisha Tijare, Shreenivas Kallianpur and Sandeep Gupta (2013), " A Cross-Sectional Study on the Knowledge of Hepatitis B Infection among Dental Professionals," Journal of Virology \& Microbiology, Vol. 2013 (2013), Article ID 288280, DOI: $10.5171 / 2013.288280$ 


\section{Introduction}

The most common inflammatory disease of the liver is due to hepatitis B (HBV) caused by a double stranded DNA virus of the hepadnaviridae. This virus can survive outside the body for at least seven days and the incubation period is of 21-135 days (Sharma R et al. 2004). Seven types of hepatitis virus are identified and named as hepatitis $A$ to $G$, of which $F$ is hypothetical and hepatitis $B$ remains the most serious type with high risk of death from liver cirrhosis and cancer.

There are more than two billion people worldwide, having evidence of recent or past HBV infection and 350 million are chronic carriers(Malik A.H.et al. 2000). India is at the intermediate endemic level of hepatitis B with more than 40 million HBsAg carriers accounting for $9 \%$ of the total carriers worldwide (Rao M.B 2012).

Hepatitis B, C and D are transmitted by parenteral contact with infected body fluids including blood, semen, saliva, sweat and tears, invasive medical procedures using contaminated equipment, vertical transmission and from family member to child. Whereas hepatitis A, E, G are typically caused by ingestion of contaminated food or water.

HBV is 50 to 100 times more infectious than HIV and is a major occupational risk for physicians, surgeons and serious problem of public health and a major cause of morbidity and mortality especially in developing countries (Adoga, M.P et al. 2010 \& WHO Online, 2000). However, the incidence of HBV infection can be reduced by giving proper education regarding its transmission and immunization to public, all healthcare workers (HCWs) and students.

Although vaccines against HBV infection are available since 1982 and are shown to be 95\% effective in preventing infection, still a dearth of adequate knowledge of Hepatitis B infection and vaccine exists in India. (Misra B et al l. 2009 \& Bhaumik P et al. 2011).Thus, an emphatic awareness and immunization programme can be helpful to reduce the further progression of this disease. Medical and dental professionals and other HCWs are at a higher risk of acquiring HBV compared to the other population. So, the present study was designed to assess and compare the knowledge about hepatitis $B$ infection in different institutions among the dental practitioners and students of Bhopal city and to make them aware of HBV vaccination.

\section{Materials and Methods}

A stratified random cross sectional study was conducted at four different institutions in Bhopal city (Central India). A pre-structured questionnaire was distributed to 280 individuals which were divided into 3 strata comprising of 80 dental practitioners (group A), 100 dental postgraduate students (group B) and 100 dental interns (group C).Since the list of the above mentioned dental professionals was easily available, subjects included in the study were chosen by lottery method of random sampling.

The questionnaire consisted of twenty questions categorized under five headings namely hepatitis infection and its transmission, vaccination, investigation and diagnostic procedures, attitude towards the HBV positive patients and post exposure prophylaxis. Scoring was given as good and poor based on, more than 50\% correct answers and less than 50\% correct answers in each category respectively. SPSS (version 20) statistical software was used for data analysis and overall status of awareness of 280 individuals collectively was evaluated qualitatively using the Z- test of proportion. ANOVA test was used to compare the level of awareness among and between the three groups.

\section{Results}

Awareness and knowledge regarding hepatitis and its transmission, vaccination, attitude towards HBV patients and post exposure prophylaxis was $82.15 \%, 95.36 \%$, $58.22 \%$ and $93.93 \%$ respectively. While only 
$41.79 \%$ had correct knowledge regarding investigation and diagnosis of hepatitis. (Fig 1). However when the comparison was done between $\mathrm{A}, \mathrm{B}$ and $\mathrm{C}$ groups the results were found to be statistically not significant. (Table 1)

Status of Awareness/ Attitude of Hepatitis

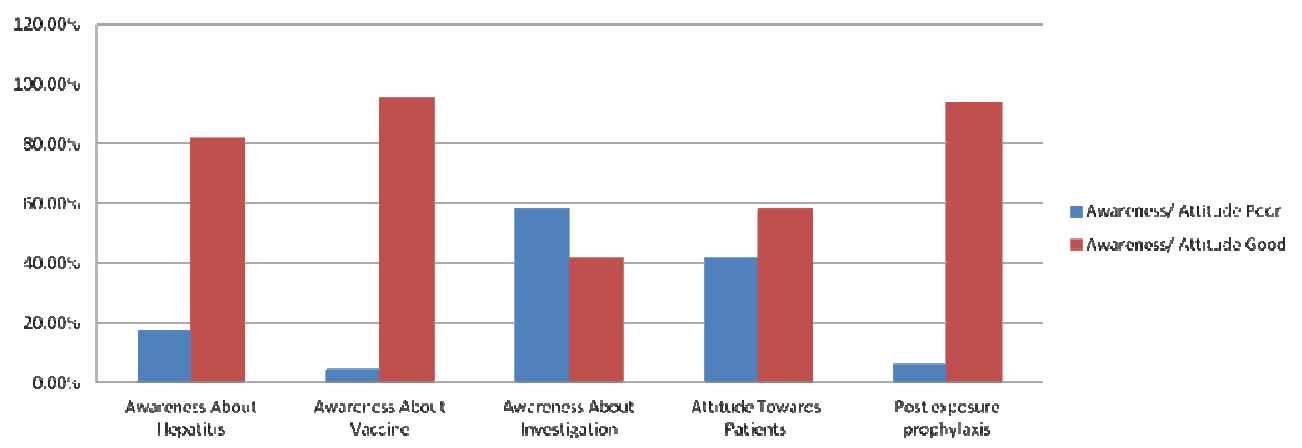

Table 1- Comparison of Awareness/Attitude about Hepatitis among Different Groups

\begin{tabular}{|c|c|c|c|c|c|c|}
\hline Parameters & Groups & Mean & SD & $\mathbf{N}$ & $\begin{array}{l}\text { F- Value(one } \\
\text { Way ANOVA) }\end{array}$ & p-Value \\
\hline \multirow{3}{*}{$\begin{array}{l}\text { Awareness About } \\
\text { Hepatitis \& its } \\
\text { transmission }\end{array}$} & Group A & 6.54 & 1.259 & 80 & \multirow{3}{*}{2.538} & \multirow{3}{*}{$\begin{array}{l}0.081 \\
\text { NS }\end{array}$} \\
\hline & Group B & 6.96 & 1.84 & 100 & & \\
\hline & Group C & 6.53 & 1.33 & 100 & & \\
\hline \multirow{3}{*}{$\begin{array}{l}\text { Awareness } \\
\text { About Vaccine }\end{array}$} & Group A & 3.481 & 0.860 & 80 & \multirow{3}{*}{1.505} & \multirow{3}{*}{$\begin{array}{l}0.224 \\
\text { NS }\end{array}$} \\
\hline & Group B & 3.515 & 0.691 & 100 & & \\
\hline & Group C & 3.32 & 0.956 & 100 & & \\
\hline \multirow{3}{*}{$\begin{array}{l}\text { Awareness } \\
\text { About Investigation }\end{array}$} & Group A & 1.30 & 0.585 & 80 & \multirow{3}{*}{2.230} & \multirow{3}{*}{$\begin{array}{c}0.109 \\
\text { NS }\end{array}$} \\
\hline & Group B & 1.39 & 0.512 & 100 & & \\
\hline & Group C & 1.47 & 0.521 & 100 & & \\
\hline \multirow{3}{*}{$\begin{array}{l}\text { Attitude To } \\
\text { Wards HBV } \\
\text { positive Patients }\end{array}$} & Group A & 1.8 & 0.891 & 80 & \multirow{3}{*}{2.819} & \multirow{3}{*}{$\begin{array}{l}0.061 \\
\text { NS }\end{array}$} \\
\hline & Group B & 1.94 & 1.309 & 100 & & \\
\hline & Group C & 1.58 & 0.955 & 100 & & \\
\hline \multirow{3}{*}{$\begin{array}{l}\text { Post exposure } \\
\text { prophylaxis }\end{array}$} & Group A & 0.937 & 0.244 & 80 & \multirow{3}{*}{2.314} & \multirow{3}{*}{$\begin{array}{l}0.101 \\
\text { NS }\end{array}$} \\
\hline & Group B & 0.98 & 0.141 & 100 & & \\
\hline & Group C & 0.91 & 0.288 & 100 & & \\
\hline
\end{tabular}

\section{Discussion and Conclusion}

Hepatitis B is a dreaded infectious disease and global public health problem which mainly affects liver functioning and sometimes causes irreversible liver injury. Symptoms range from a short asymptomatic period or mild to potentially fatal and acute to chronic liver disease resulting in either cirrhosis or hepatocellular carcinoma.
In India, approximately 3 to $4 \%$ of the population is infected with virus and more than $50 \%$ cases are of chronic hepatitis. HBV epidemiology in India becomes relevant nationally and internationally, possibly because India may become the largest pool in world (Chowdhury A. 2004).

Most of the HCWs in India do not observe proper protocol on a regular basis during their clinical practice along with lack of 
knowledge regarding HBV transmission and its consequence. So the present survey was emphasized to know the awareness regarding hepatitis $\mathrm{B}$ and $\mathrm{HBV}$ prophylaxis among dental students and practitioners from their perspective.

In the present study, of the 280 subjects, $82.15 \%$ showed a good level of awareness regarding the epidemiology and the route of transmission of hepatitis and $95.36 \%$ had good knowledge about vaccination of hepatitis B, almost at par with survey among 150 undergraduates dental students in Maharashtra conducted by Saini R et al. 2010, in which $81.55 \%$ and $94 \%$ were correct regarding their knowledge about transmission and vaccination respectively.

In another study conducted by Singh, A. \& Jain,S. 2011 to assess the knowledge and status of hepatitis B vaccination among the medical students, $86.7 \%$ were aware about hepatitis $B$ virus with the majority having correct knowledge regarding mode of transmission. In the survey done to determine the vaccination status, knowledge, attitude and practice regarding hepatitis $\mathrm{B}$ and $\mathrm{C}$ among medical students of Karachi by Khan, $\mathrm{N}$ et al. 2010, the results obtained were significantly lower i.e. only $57.1 \%$ had knowledge about the routes of spread and only $85 \%$ were aware of vaccine for hepatitis $\mathrm{B}$ when compared to the present study.

In a survey by Sivarajasingam, V et al. 1995, 99.2\% medical and dental students were aware of HBV immunization whereas only $92.9 \%$ of medical and dental interns of Pondicherry conducted by Tirounilacandin P et al. 2009 were aware of immunization against HBV as compared to the our survey.

In the Present study, 93.93\% had correct knowledge regarding post exposure prophylaxis in contrast to a study where $76 \%$ did not have the knowledge regarding post exposure prophylaxis (Khan, $\mathrm{N}$ et al. 2010). Whereas in one more study ,the majority of third year undergraduate students gave correct answers while only $20 \%$ of the second year had the correct knowledge regarding the same(Singh, A. \& Jain,S.,2011).
In this study $58.22 \%$ showed a positive attitude towards $\mathrm{HBV}$ patients with an insignificant difference between three groups regarding the same indicating that the hepatitis patients should not be avoided but treated by taking proper precautionary measures which is similar to a study by Khan, $\mathrm{N}$ et al. 2010.

Whereas $89 \%$ showed a good level of knowledge about the investigation and diagnosis of hepatitis $\mathrm{B}$ and $\mathrm{C}$ according to Khan, $\mathrm{N}$ et al. 2010. which was in contrast with the present survey were only $58.21 \%$ gave correct answers. The present study also revealed insignificant differences in the levels of the awareness among the three groups in all the categories.

So to conclude scientific knowledge regarding HBV transmission is essential for any medical professional students since they have to take the proper protection during their clinical posting as $\mathrm{HBV}$ is easier to transmit than HIV .

The study reveals that more efforts and preventive measures to be taken by these students to prevent acquiring this deadly infection by getting themselves vaccinated as they get admission into such courses as well as by taking booster doses at proper intervals, without which they become more vulnerable for infection.

Timely and suitable prophylaxis following the exposure to HBV can prevent the infection and subsequent development of the chronic infection or the liver disease. Thus, this study also reflects the need of advising screening and diagnostic tests for HBV in patients who are clinical suspects of the disease undergoing minor and major surgical procedures. The professionals should be aware of post exposure prophylaxis regimen in case of any accidental exposure to HBV. Immediate treatment following the percutaneous injury includes washing the exposure site with soap and water; mucous membrane and eyes should to be flushed with water only (Singhal, V et al. 2009).

As recommended by centers for disease control and prevention (CDC), post exposure 
prophylaxis includes hepatitis B immunoglobulin (HBIG) and/or hepatitis B vaccine series which should be initiated within $24 \mathrm{hrs}$ to latest 1 week from the time of exposure after evaluation of the hepatitis $B$ surface antigen status of the source and the vaccination and vaccine-response status of the exposed person (Centres for Disease Control and Prevention, 2001).

However this survey was aimed at a random population of dental professionals so the findings cannot be generalised to all the professional individuals. But the knowledge can be further enhanced by conducting continuing dental education (CDE) programme, seminars and workshops about hepatitis B infection at institutional level as "awareness is empowering".

\section{References}

Adoga, M.P.,Gyar, S.D., Pechulano,S., Bashayi,O. D.,Emiasegen, S.E. \& Zungwe,T.etal. (2010). "Hepatitis B virus infections in apparently healthy urban Nigerians: data from pre-vaccination tests," J Infect DevCtries, 4(6), 397-400.

Bhaumik,P.,Choudhury,A.R.\&Sinha,P. (2011). "Combating Hepatitis B: The Tripura Model," Euroasian Journal of Hepato Gastroenterology,1 (2),39-41.

Centres for Disease Control and Prevention (2001).Updated U.S. Public Health Service Guidelines for the Management of Occupational Exposures to HBV, HCV, and HIV and Recommendations for Postexposure Prophylaxis.[Retrieved August 30,2012] Available:http://www.cdc.gov/mmwr/previe $\mathrm{w} / \mathrm{mmwrhtml} / \mathrm{rr} 5011 \mathrm{a} 1 . \mathrm{htm}$.

Chowdhury,A.(2004).“Epidemiology of Hepatitis B virus infection in India,"Hep B Annual1(1),17-24.

Khan,N.,Ahmed,S. M.,Khalid,M. M.,Siddiqui,S. H.\&Merchant,A.A.(2010)."Effect of gender and age on the knowledge, attitude and practice regarding Hepatitis $\mathrm{B}$ and $\mathrm{C}$ and vaccination status of Hepatitis $B$ among medical students of Karachi, Pakistan,"J Pak Med Assoc,60(6), 450-455.

Malik,A.H. \& Lee,W.M.(2000). "Chronic Hepatitis B Virus Infection. Treatment Strategies for the next Millenium,"Annals of Internal medicine, 132 (9),723-31.

Misra,B.,Panda,C.,Das,H. S.,Nayak, K. C. \& Singh, S.P.(2009)."Study on awareness about Hepatitis B viral infection in eastern coastal, India,"Hepatitis B Annual, 6 (1),19-28.

Rao,M.B.,(2012)."The prevalence of hepatitis $\mathrm{B}$ in India and its prevention with Ayurveda a revisit,"Journal of New Approaches to Medicine and Health,19 (4).

Saini,R.,Saini,S.\&Sugandha,R.S.(2010).“Knowl edge and awareness of hepatitis B infection amongst the students of Rural Dental college,Maharashtra,India,"Annals of Nigerian Medicine,4(1),18-20.

Sharma,R.,Sharma,C.L.\&Khajuria,R.(2004). "The Knowledge ,Attitude and Practices regarding HBV infection of married women in reproductive age group living in cantonment area ,Sunjawan,Jammu,"JK Science,6(3),127-30.

Singh,A.\&Jain,S.(2011)."Preventionof Hepatitis B; Knowledge and practices among Medical students,"Healthline, 2( 2),8-11.

Singhal,V.,Bora,D.\&Singh,S.(2009).“Hepatitis B in Health Care Workers: Indian Scenario," J Lab Physicians,1(2),41-48.

Sivarajasingam,V.,Laszlo,J.\&Ogden,G.R.,(1995 )."Extent of hepatitis B immunisation among medical and dental students,"British Medical Journal, 311(6999),231.

Tirounilacandin, P., Krishnaraj, S., \& Chakravarthy, K.(2009). "Hepatitis B infection: Awareness among medical,dental interns in India". Ann Trop Med Public health :(2):33-36

World Health Organization. Hepatitis B Fact Sheets.(Online)2000.[retrievedAugust25,201 2] Available:

http://www.who.int/mediacentre/factsheets /fs204/e 